\title{
DESAFIOS EMERGENTES NA AÇÃO EDUCATIVO-AMBIENTAL: UMA EXPERIÊNCIA EM CENTROS DE EDUCAÇÃO INFANTIL DE CURITIBA - PR
}

\author{
M. A. T. CAMPOS ${ }^{*}$ e A. M. CARVALHO \\ Universidade Federal do Paraná - UFPR \\ mariliat.ufpr@gmail.com
}

Artigo submetido em outubro/2013 e aceito em agosto/2015

DOI: $10.15628 /$ holos.2015.1698

\section{RESUMO}

A inserção da educação ambiental nos cenários educativo-institucionais aponta para a criação de alternativas necessárias frente às evidências de uma crise ambiental. Com esta perspectiva, a análise da práxis dos docentes é importante para avaliar as propostas educativas desenvolvidas em Centros de Educação Infantil, tomando como referência o ponto de vista e a ação dos professores. O objetivo deste trabalho foi a análise feita a partir da elaboração de um conjunto de estratégias de intervenção estimuladoras de um diálogo efetivo entre as acadêmicas do curso de Pedagogia e a realidade profissional que as professoras vivenciam em um Centro Municipal de Educação Infantil (CMEI) de Curitiba, considerando suas práticas e discursos no que se refere à temática educativoambiental. A compreensão da proposta pedagógica da escola foi o ponto de partida para estruturar a proposta de intervenção e o estabelecimento de diálogo com as profissionais que atuam no CMEI. Através de entrevistas e aplicação de questionários a dez professoras, foi possível identificar as características das práticas de educação ambiental elaboradas e efetivadas pelas professoras e educadoras. As professoras se manifestaram positivamente sobre a necessidade de que iniciativas como essa sejam repetidas nos próximos anos e que o número de CMEls participantes fosse ampliado. Acredita-se que os resultados obtidos por meio desta pesquisa possam contribuir para repensar o processo de inserção da educação ambiental no contexto educativo institucional e para a elaboração de políticas públicas coerentes com as necessidades manifestadas pelas profissionais que participaram deste processo coletivo de aprendizagens.

PALAVRAS-CHAVE: Educação Ambiental, Educação Infantil, Práxis.

\section{EMERGING CHALLENGES IN ENVIRONMENTAL EDUCATION ACTION: AN EXPERIENCE IN EARLY CHILDHOOD EDUCATION CENTERS OF CURITIBA - PR}

\begin{abstract}
The inclusion of environmental education in formaleducational scenarios points to the creation of viable alternatives in the face of evidence of an environmental crisis and the analysis of the practice of teachers is important to assess the institutional educational proposals with reference to the views of teachers. This work aimed to propose an intervention strategy of stimulating an effective dialogue between Pedagogy students and the professional reality that teachers experience at a Municipal Center for Early Childhood Education (CMEI) of Curitiba, through analysis of practices and discourses of teachers with regard to educational and environmental themes. The understanding of the school pedagogy was the starting point to structure our proposed intervention and to establish the dialogue with professionals that work at the CMEI. Through interviews and questionnaires to ten
\end{abstract}

teachers, we could identify the practice of environmental education activities, but practices that are not tied to institutional projects or interconnected. At the end of the project we developed an educational workshop to strengthen the work on environmental education and encourage the adoption of new practices related to the development of environmental values. The teachers have spoken positively about the need for initiatives like this be repeated in the coming years and that the number of participant CMEls be expanded. We believe that the results obtained through this research may contribute to rethink the process of inclusion of environmental education in institutional and educational context and for the elaboration of public policies consistent with the needs expressed by professionals who participated in the project.

KEYWORDS: Environmental Education, Childhood Education, Praxis. 


\section{INTRODUÇÃO}

A educação ambiental é um campo pedagógico diverso e de especial interesse, que se legitima na complexidade do campo da educação e das ciências ambientais. Sendo assim, e considerando que o processo educativo é uma prática com decorrências sociais, políticas e ideológicas, se toma por objeto de análise a práxis dos docentes como aporte para compreender e avaliar as propostas educativas institucionais. Nesse sentido, valeria sublinhar que a inserção da Educação Ambiental nos múltiplos espaços de vida e especialmente nos espaços educativoformais, em que os professores desenvolvem sua ação profissional, pode apontar para um cenário de alternativas frente às evidências latentes de uma crise ambiental.

Este artigo tem como base a experiência de um projeto de pesquisa e extensão intitulado "A práxis da Educação Ambiental nos Centros Municipais de Educação Infantil do município de Curitiba, PR" desenvolvido no âmbito do Programa Licenciar da Universidade Federal do Paraná (UFPR) nos anos de 2011 e 2012. O referido programa visa propor uma estratégia de diálogo efetivo entre os acadêmicos do curso de Pedagogia com a realidade profissional que os professores vivenciam nos Centros Municipais de Educação Infantil (CMEIs) de Curitiba. Através da análise de práticas e discursos de docentes dos Centros no que se refere à temática educativoambiental e a proposição de experiências com as crianças, as acadêmicas puderam interagir com a realidade da Educação Infantil e construir novos conhecimentos sobre a docência.

Esta experiência revelou a necessidade de inserção da temática educativo-ambiental nas propostas formativas das instituições de ensino superior, pois estas tem papel essencial no processo de produção de conhecimentos e na incorporação das atuais dimensões científicas, tecnológicas e culturais à pesquisa na educação (MORALES; KNECHTEL, 2012). Esta realidade é ainda mais marcada quando se trata da formação de professores, pelo forte impacto social que tem a ação dos educadores na formação das novas gerações. Também seria imperativo destacar que a formação dos docentes não se constitui apenas em uma etapa formativa delimitada no tempo e no espaço, tendo em vista que o processo de formação e edificação dos saberes utilizados pelos professores para realizarem suas tarefas profissionais são o resultado de um conjunto de fatores que influem ou determinam sua ação e seu pensamento, conforme aponta Tardif (2002).

\section{A EDUCAÇÃO AMBIENTAL NO CONTEXTO DA EDUCAÇÃO INFANTIL}

Segundo García (2004), o campo da educação ambiental se caracteriza pela diversidade. Não existe uma única concepção de educação ambiental e, apesar de esta diversidade ser enriquecedora, também dificulta a reflexão e a ação, por falta do consenso de um eixo de conhecimento de referência. Porém, em um aspecto todos estão de acordo: a educação ambiental pretende propiciar uma mudança de pensamento e a conduta das pessoas e dos grupos sociais; a divergência está em como se caracteriza esta mudança: seu sentido, seu conteúdo, as estratégias utilizadas, a amplitude da mudança proposta, entre diversos outros aspectos.

A conjugação entre as diversas oportunidades de construção do conhecimento oferecidas pela educação formal, a partir de processos de estruturações cognitivas e afetivas dos sujeitos, poderia, assim, potencializar a compreensão das questões ambientais como questões sócio- 
políticas e, por conseguinte, merecedoras de um olhar crítico, contribuindo para a construção de uma nova racionalidade, ou melhor, cooperando para a construção de uma racionalidade ambiental. Com essas considerações, justifica-se o interesse teórico em compreender a práxis da educação ambiental desde a perspectiva dos professores, buscando respostas na interface entre o individual e o social, como forma de aportar dados que ajudem a elucidar o processo de efetivação da educação ambiental no contexto educativo-escolar.

É importante lembrar que a educação ambiental surge junto com os movimentos ambientalistas e de "contra-cultura" dos anos 1960 com a proposta de combate à destruição ambiental que vinha (e vem) crescendo exponencialmente. Nesse breve percurso, a educação ambiental deparou-se com o desafio de cumprir com a função de "incorporar a dimensão ambiental não apenas na educação, mas em todo o tecido social, em todas as manifestações simbólicas e materiais do ser humano" (LAYRARGUES, 2001, p. 8), tendo em vista a amplitude das implicações que o tema revela. De acordo com as conclusões da Conferência InterGovernamental de Tbilisi (Geórgia), realizada em outubro de 1977 e considerada como um dos eventos-chave na discussão da temática, a educação ambiental poderia ser considerada "como uma dimensão dada aos conteúdos e à prática da educação orientada para a resolução dos problemas concretos do ambiente, através de enfoques interdisciplinares e de uma participação ativa e responsável de cada indivíduo e da coletividade". Esta opção é coerente com o caráter amplo e complexo do tema, que envolve distintas áreas de conhecimento e é, inevitavelmente, incompatível com uma visão unidisciplinar. Através dos documentos legais orientadores das políticas de educação ambiental, percebe-se que este processo deve fazer parte do processo educativo formal, ou seja, deveria ser efetivado nas escolas e, também, nos Centros de Educação Infantil.

Diversos modelos de educação ambiental conhecidos como convencionais buscam educar ambientalmente para a mudança de conhecimentos, valores, hábitos e comportamentos, atitudes etc. (MEIRA CARTEA, 2006). Porém segundo este autor tais modelos acabam não assumindo a natureza estrutural da crise ambiental, ou seja, não entendem a problemática ambiental como um desajuste do funcionamento das sociedades contemporâneas e acabam confinados pelos limites que impõem a mesma lógica do sistema no qual estão inseridos. Como exemplo, em relação ao destino de resíduos, tema recorrente nas práticas educativo-ambientais, se estimula continuamente a Política dos 3R's (reduzir, reutilizar e reciclar) sem necessariamente discutirem a fundo a questão do consumismo, da obsolescência programada e da criação de demandas artificiais no capitalismo (LAYRARGUES, 2002).

Ao abordar a ação educativo-ambiental para crianças de 0 a 6 anos, e tendo em vista os conceitos dos autores citados, é um desafio pensar em projetos permanentes e emancipatórios, que considerem a importância de compreender a percepção e a sensibilização das crianças em relação ao meio ambiente, visto que a compreensão de mundo dessas crianças ainda está em processo inicial de formação e os professores demonstram despreparo teórico e metodológico em relação ao tema.

Nas últimas décadas, a Educação Infantil tem avançado positivamente em diversos aspectos, impulsionada pelas profundas transformações sociais que se refletem na própria estrutura das famílias e em sua função educativa. Essas mudanças exigem um maior conhecimento sobre o comportamento das crianças e seu potencial de aprendizagem, além de uma maior divulgação e reconhecimento dos direitos fundamentais da infância. Como resultado 
desse processo de mudança, a Educação Infantil está entrando em uma nova etapa, em que se exige docentes com um novo conhecimento e competências específicas para realizar seu labor educativo (PARRA ORTIZ, 2005).

$\mathrm{Na}$ medida em que aumentam as pesquisas sobre as variáveis sociais, psicológicas, educativas e políticas da Educação Infantil, aumenta a necessidade de conceber esta etapa educativa com suas características identitárias próprias, que responda às seguintes metas formativas essenciais, conforme aponta Frabboni (1996, p. 193):

- A primeira meta é garantir às crianças que frequentam a escola infantil a recuperação e ativação das suas necessidades educativas, com uma referência particular às que atualmente estão desvalorizadas, restringidas pela sociedade deste começo de século e comprometidas no âmbito familiar: como a necessidade de comunicação, socialização, fantasia, movimento, exploração, construção, aventura etc.

- A segunda meta é converter a escola infantil em um centro de cultura que permita às crianças inter-atuarem em campos de experiência cognitivo-expressivo particularmente significativos para a segunda infância: os campos da experiência corporativa, da comunicação, da lógica e do ambiente. A estes campos cognitivoexpressivos acrescenta-se o horizonte dos valores, que objetiva fazer com que a infância se encontre nos modelos de vida social, afetiva, moral e religiosa que interatuam com a coletividade.

- No Brasil, a Educação Infantil tem sido alvo de muitos debates, principalmente depois que a Lei de Diretrizes e Bases (LDB/96) foi aprovada. Nela se estabelece o direito de acesso a este nível de ensino, como direito adquirido pelas crianças e suas famílias, em contrapartida ao dever do estado em garantir o oferecimento deste serviço. Segundo Parra Ortiz (2005), a Educação Infantil se qualifica pedagógica e didaticamente quando se abre para o exterior e interage, comunicando-se com outros agentes e forças sociais como a família, os agentes sociais, os entes locais, os meios de comunicação e faz do ambiente exterior um fértil terreno de experiência formativa.

Tendo em vista as características desta etapa educativa, vale ressaltar que do universo de implicações que a Educação Infantil envolve, focaliza-se o interesse na ação de um elemento em especial, ou seja, o trabalho realizado pelos professores e suas múltiplas implicações, especialmente no que se refere à formação de atitudes, valores e comportamento relacionados ao meio ambiente, tendo em vista que a experiência infantil se qualifica quando se abre para o exterior e interage, comunicando-se com outros agentes sociais e com o ambiente exterior.

\section{AS PRÁtICAS DE EDUCAÇÃO AMBIENTAL NOS CENTROS MUNICIPAIS DE EDUCAÇÃO INFANTIL}

A seleção do CMEI no qual seria realizada a intervenção foi feita pela Secretaria Municipal de Educação de Curitiba. Após a escolha do Centro, realizou-se, através de reuniões com a pedagoga e a diretora, um diagnóstico do CMEl. Este processo permitiu a obtenção de dados como o número de alunos matriculados, as características do quadro de funcionários, formação dos funcionários administrativos e docentes, a dinâmica das rotinas e a estrutura física dos espaços. Por outro lado, também foi possível compreender o perfil da comunidade ao seu redor do CMEI (renda média das famílias, perfil de trabalho, participação no CMEI etc.) e a percepção da diretora, pedagoga, professoras e educadoras sobre a temática ambiental. 
Com base no diagnóstico realizado e com o objetivo de analisar a práxis da educação ambiental neste $\mathrm{CMEl}$, foram definidos oito objetivos: 1) identificar práticas de educação ambiental na educação infantil; 2) identificar iniciativas/práticas individuais de educação ambiental; 3) relacionar práticas de educação ambiental com os recursos teóricos utilizados pelas professoras; 4) descrever o perfil formativo-profissional das docentes e educadoras; 5) analisar a concepção das professoras em relação à problemática ambiental da comunidade em que o CMEI está inserido; 6) compreender a finalidade pedagógica da horta na escola; 7) identificar o nível de envolvimento da comunidade nas atividades de educação ambiental; e 8) identificar a rede de colaboração que o CMEl estabelece para desenvolver práticas de educação ambiental.

Para alcançar cada um desses objetivos, foram utilizadas três fontes para coleta de dados e posterior intervenção: a observação, a análise de documentos e os questionários. Os dados da observação foram as informações coletadas na primeira conversa com a pedagoga e a diretora do $\mathrm{CMEI}$, além do o reconhecimento visual do espaço físico do Centro. Em uma segunda etapa, foi realizada a leitura e análise de documentos com referências à prática de educação ambiental no $\mathrm{CMEI}$, como os Planos Anuais e planejamentos de turmas, por exemplo. Os questionários foram fornecidos impressos e digitalizados às professoras e educadoras. A proposta inicial era que fossem realizadas entrevistas com todas as docentes do Centro ou, pelo menos, com uma de cada turma. Porém, pela escassez de tempo, optou-se por substituir as entrevistas por questionários que as professoras/educadoras pudessem responder sozinhas, quando tivessem disponibilidade. Ainda assim, foi realizada uma entrevista com uma das professoras.

Através da análise do diagnóstico, dos dados coletados e das respostas dos questionários foram selecionadas diversas atividades de Educação Ambiental possíveis de serem realizadas na Educação Infantil e que foram apresentadas em uma Oficina realizada para as professoras/educadoras do CMEl ao final do projeto.

O CMEI de atuação do projeto atende 130 crianças, divididas em Berçário, Maternais I, II e III e Pré. O Centro atende uma comunidade com renda variando entre média-baixa e média, praticamente todos os pais/mães possuem emprego fixo com carteira assinada e os empregos são bastante variados, como comércio, indústria, saúde, serviço público, empresas privadas etc. Os pais são participativos nas atividades propostas pelo Centro, sempre vão às reuniões e gostam de contribuir para a melhoria do CMEI.

\section{AS PRÁTICAS DE EDUCAÇÃO AMBIENTAL: CARACTERÍSTICAS E DESAFIOS}

Através da observação e das conversas com a diretora e a pedagoga, percebeu-se que o CMEI não realiza projetos institucionais de Educação Ambiental que envolvam todo o Centro; todos os projetos e atividades sobre a temática ambiental são realizados dentro das turmas e de forma pontual, não há projetos de longa duração. Segundo as duas profissionais, se as crianças se interessam pelo tema de alguma atividade que foi realizada, as professoras dedicam mais tempo a essa temática, realizando mais atividades, mas sem chegar a transformar esse prolongamento em um projeto de longa duração.

Os únicos projetos que foram realizados institucionalmente para todo o CMEI foram o plantio de mudas de flores em pneus velhos, no qual cada turma plantou cinco mudas, e a horta, que foi criada através de uma parceria do Centro com a Secretaria Municipal do Abastecimento 
de Curitiba. A horta é bastante pequena $(3 \mathrm{~m} \times 1 \mathrm{~m})$, mas todas as crianças participam de seu cultivo, manutenção e colheita. Porém pôde-se perceber que a horta está mais voltada à questão da alimentação das crianças e do envolvimento delas com seu próprio alimento do que sendo usada como um instrumento para a prática da educação ambiental. Logo que foi organizada a horta, a pedagoga e a diretora convidaram uma nutricionista para fazer uma palestra para toda a comunidade sobre alimentação saudável.

Em relação às problemáticas ambientais que circundam o $\mathrm{CMEI}$, foi possível perceber um grande transtorno causado por um posto de gasolina localizado ao lado do Centro. O cheiro de gasolina é bastante forte ao redor da quadra onde se localiza o posto e o CMEI, causando mal estar nas pessoas que frequentam o local. Além disso, segundo a diretora e a pedagoga, sempre que os funcionários do posto lavam o chão, escoam toda a gasolina para o $\mathrm{CMEI}$, causando grandes riscos a segurança. Esta realidade nos leva a pensar na necessidade de tratar de uma educação ambiental crítica, que permita uma análise mais profunda da realidade e da estruturação de reações coletivas sobre ela, pois não basta identificar os problemas, é preciso capacidade de buscar alternativas para melhorar as condições ambientais imediatas.

Através da análise de documentos, percebeu-se que no CMEI não há nenhum livro específico sobre Educação Ambiental, o que faz com que as professoras/educadoras tenham que recorrer à Internet, revistas ou às colegas quando desejam buscar informações sobre o tema enquanto estão no CMEI. Este dado leva a pensar na autonomia dos professores e na responsabilidade dos mesmos com sua constante formação. A biblioteca escolar é um espaço favorável ao acesso a informações e aos recursos teórico-metodológicos que auxiliam no aprimoramento das práticas pedagógicas escolares, no entanto, a qualidade dos materiais disponíveis é um balizador para o avanço das propostas formativas.

Como definido pela Secretaria Municipal de Educação de Curitiba, todas as atividades planejadas pelas professoras devem se enquadrar em alguma das Áreas de Formação Humana (identidade, linguagem oral, escrita e leitura, movimento, artística, pensamento lógicomatemático e relações sociais e naturais). Neste sentido, analisando os Planos Anuais de 2011 percebeu-se que é somente na área "Relações Sociais e Naturais" que aparece esporadicamente alguma menção de atividade relacionada ao meio ambiente. No Berçário, as atividades desta área humana são muito mais sociais do que ambientais. Já no Maternal I, mais elementos ambientais aparecem. Um dos objetivos gerais desta área para esta turma é: "aprender sobre o mundo que a cerca pela observação dos fenômenos naturais, pela exploração de elementos da natureza e de outros objetos" e alguns dos objetivos específicos são: "perceber que suas atitudes geram consequências nas relações sociais e naturais", "manusear elementos da natureza" e "observar seres vivos e seus modos de vida". Já no Maternal II um dos objetivos gerais da área que mais se aproxima de uma atividade de Educação Ambiental seria: "oportunizar vivências que promovam a percepção da importância de ações e posturas positivas na qualidade de vida", e o objetivo específico que mais se encaixaria neste objetivo geral talvez fosse: "partilhar informações de sua família, identificando sua composição e modo de vida". No Pré não havia nenhum objetivo que pudesse ser classificado como educação ambiental e não foi encontrado o Plano Anual do Maternal III.

Em relação ao questionário, das vinte professoras/educadoras do $\mathrm{CMEl}$, uma foi entrevistada e nove responderam ao questionário, cujas perguntas eram as mesmas da 
entrevista. Alegando falta de tempo, várias professoras/educadoras responderam ao questionário em conjunto, totalizando em apenas dez docentes consultadas.

Segundo essas dez docentes, todas realizam atividades de educação ambiental em suas turmas. Dentre as atividades citadas estão: observação da natureza, manuseio de elementos da natureza, plantio de flores e sementes, cultivo da horta, coleta seletiva e utilização de materiais recicláveis. Essas iniciativas estão condicionadas às motivações pessoais e profissionais das professoras, por isso buscamos compreender os fatores motivacionais que determinam essa prática. Em seis dos questionários as professoras/educadoras afirmaram não participar de nenhuma iniciativa de Educação Ambiental e nos outros quatro consideraram ter "cuidado com o meio ambiente" e "aproveitar o material que temos com criatividade" como iniciativas de Educação Ambiental. Porém, nenhuma das educadoras dos quatro últimos questionários justificou os fatores que as motivaram a isso.

Segundo as professoras/educadoras, a horta do CMEI é mais utilizada para abordar aspectos da Botânica, estimular o trabalho em equipe e a organização, produzir alimentos para consumo próprio e flores para enfeitar o Centro. Apesar de não utilizarem a horta especificamente para este fim, todas a consideraram como uma importante ferramenta para a Educação Ambiental, afirmando que através dela é possível se trabalhar com os "cuidados ao meio ambiente", com a "conservação" e com a "busca de alimentos saudáveis sem agrotóxicos".

Segundo seis respondentes, não houve nenhuma participação/parceria de outras instituições nas atividades de educação ambiental realizadas pelo CMEI. Porém, segundo um dos questionários, para a realização da horta o CMEl contou com o apoio e parceria da Secretaria Municipal de Abastecimento de Curitiba, o que denota que a existência deste espaço configura um possível catalisador de parceiros externos a instituição. Além disso, em outros dois questionários foi dito que houve a participação da Secretaria Municipal do Meio Ambiente e da Secretaria Municipal de Educação, mas não foi especificado qual o teor desta parceria e qual a participação efetiva de cada um dos envolvidos.

Quanto às fontes de informação teórica ou prática que os professores utilizam para desenvolver sua prática de Educação Ambiental, as professoras entrevistadas afirmaram obter informações através de: buscas na Internet; consultas às Diretrizes Curriculares e revistas de Educação Infantil, livros, cartilhas e enciclopédias; afirmaram também que os cursos e oficinas oferecidas pela Prefeitura Municipal de Curitiba e pela Secretaria Municipal de Educação favorecem o processo.

Das dez docentes consultadas, uma delas possui apenas o Ensino Médio e nove possuem graduação (Pedagogia, História, Biologia e Letras), dentre as quais três possuem pós-graduação. Somente quatro docentes afirmaram que a questão ambiental foi tratada durante sua formação universitária e uma das professoras já realizou, por conta própria, um curso específico sobre educação ambiental, na Fundação Boticário.

Apenas três professoras/educadoras afirmaram nunca ter tido nenhuma formação em educação ambiental. Quatro delas disseram que, em cursos oferecidos pela Secretaria Municipal de Educação, foi abordada a questão ambiental, apesar de uma das educadoras ter mencionado que nunca houve nenhum curso específico para o tema, mas sim cursos da área de Ciências, no qual se falava, dentre outros assuntos, de educação ambiental. Uma das professoras/educadoras 
teve uma maior formação na área durante as duas graduações que realizou (Biologia e Pedagogia) e em cursos de especialização.

Quando indagadas sobre os problemas ambientais que identificavam ao redor do CMEI, as professoras listaram as seguintes problemáticas: muito lixo nas ruas, muitos animais abandonados, falta de árvores nas vias, falta de saneamento básico, a linha de trem que corta o bairro, o Rio Belém próximo ao CMEI que ainda não é canalizado, tráfego intenso e poluição de veículos, transbordamento de rios e, principalmente, o posto de gasolina mencionado anteriormente.

Com base nestas respostas, indagamos qual o grau de importância da participação das famílias das crianças nas atividades de educação ambiental. Sobre isto, apesar de nunca ter havido um projeto institucional de educação ambiental no $\mathrm{CMEI}$, todas as respondentes afirmaram que a participação da família e da comunidade em toda e qualquer atividade no CMEI é de extrema importância. Dessa forma, pode-se concluir que, em um projeto de educação ambiental, a participação da família seria considerada fundamental pelas professoras/educadoras.

Nesta mesma tessitura da ampliação de colaboradores nas ações educativo-ambientais do CMEI, todas as professoras afirmaram que seria muito interessante que o CMEI firmasse novas parcerias com diferentes instituições. Dentre as instituições mais citadas estão empresas privadas e instituições de ensino, como a Universidade Federal do Paraná, por exemplo. Também mencionaram a Secretaria Municipal de Meio Ambiente e ONGs que tratem da temática ambiental.

Através dos resultados obtidos nas três metodologias de análise, uma Oficina de educação ambiental foi elaborada e oferecida às professoras/educadoras do CMEI, onde foram apresentadas propostas de atividades possíveis de serem realizadas na Educação Infantil e em cada faixa etária. Também foram apresentadas as experiências vividas pelas bolsistas do projeto com educação ambiental na Educação Infantil durante suas vidas acadêmicas. Ao final das apresentações, foi realizada uma atividade prática com as professoras/educadoras e foi distribuído um material impresso para cada uma delas com a descrição detalhada de todas as atividades.

Após a realização das oficinas, as professoras foram estimuladas a manifestar sua opinião em relação ao trabalho desenvolvido pela equipe do projeto. Neste momento, houve manifestações positivas sobre a necessidade de que iniciativas como essa sejam repetidas nos próximos anos e que o número de CMEls participantes fosse ampliado. Em um segundo momento, a equipe investigadora realizou uma reunião para avaliar os resultados obtidos e considerou como pontos fortes: a articulação entre a universidade e os Centros Municipais de Educação Infantil; a contribuição que as experiências vivenciadas no projeto trouxeram à formação das bolsistas; o aprofundamento teórico de todos os participantes em relação à educação ambiental; e o estímulo que as bolsistas tiveram para continuar participando de outros projetos semelhantes a este.

No ano de 2012 o projeto "A Práxis da Educação Ambiental em Centros Municipais de Educação Infantil de Curitiba, PR" manteve suas atividades no mesmo CMEI, porém com um novo enfoque: a aplicação de um projeto de educação ambiental desenvolvido em parceria com as professoras/educadoras do Centro e com duração de oito meses. 


\section{CONSIDERAÇÕES FINAIS}

Nesta pesquisa foi possível perceber que os discursos das professoras e educadoras são fortemente ambientalistas e tradicionais, nas quais a educação ambiental está mais centrada na descrição da natureza e dos problemas ambientais do que em suas causas e na capacitação para a ação. Esta realidade denota a existência de um modelo educativo-ambiental com enfoque na mudança de hábitos e rotinas sem necessariamente questionar o modelo social dominante e suas implicações. Enfoque este decorrente de um pensamento simplificador e cartesiano, produto de uma ciência positivista fortemente enraizada em nossa sociedade e principalmente em nossas escolas.

As docentes se sensibilizam, sim, pelas problemáticas ambientais que as circundam ou que identificam, entretanto não possuem consciência histórica destas problemáticas e ferramentas ideológicas para uma ação mais profunda e efetiva. Percebe-se, nesses discursos, certa "ingenuidade" e uma fragilidade no pensamento, que está distante dos modelos contrahegemônicos mais revolucionários, como afirma Loureiro (2004, p. 94):

A educação ambiental emancipatória e transformadora parte da compreensão de que o quadro de crise em que vivemos não permite soluções compatibilistas entre ambientalismo e capitalismo ou alternativas moralistas que descolam o comportamental do histórico-cultural e do modo como a sociedade está estruturada.

O que se percebe ainda é a ausência de um modelo didático explícito que guie a intervenção das professoras e que tenha como objetivo dar coerência à prática e estimular uma reflexão crítica e profunda sobre a racionalidade dominante. Percebe-se, de fato, a ausência de uma práxis inovadora, dialógica e cotidiana que aponte a essas professoras novos rumos transformadores da sociedade. É nítido o abismo que continua a existir entre as especulações dos pesquisadores teóricos e das atuações práticas dos professores, em especial no que se refere à problemática ambiental.

De forma mais ampla, um aspecto que fica bastante explícito ao final deste estudo, é a necessidade da criação de programas de pesquisa vinculados à intervenção, como acontece nos programas de extensão das universidades, no qual é feito um exercício de percepção de que se o que se estuda na academia tem articulação com o contexto da realidade ou não.

Além disso, se percebe também, a necessidade de um maior investimento na formação de educadores ambientais (sejam eles professores ou não) através da inclusão da educação ambiental como uma área de formação em todos os cursos de graduação e profissionalizantes. $E$, em conjunto com este trabalho, promover a integração e a troca de experiência dos que já atuam nesta área com o objetivo de reduzir as disputas que existem entre as diversas formações destes profissionais e estimular o intercâmbio de ideias entre estes setores e, assim, tentar superar as visões parciais dentro da educação ambiental.

Por fim, seria importante destacar que este projeto de intervenção e de pesquisa se insere em um contexto atual e pujante, no qual a temática ambiental se constitui como objeto de interesse e necessidade social. Nesse sentido, a inserção da educação ambiental nos múltiplos espaços de vida e especialmente nos cenários educativo-formais, em que os professores desenvolvem sua ação profissional, aponta uma alternativa frente às evidências latentes de uma 
crise ambiental. Ademais, considerando a repercussão do trabalho dos professores no âmbito social e a problemática evidenciada, este projeto pretendeu ser uma contribuição relevante para o avanço dos processos socioambientais, bem como uma contribuição para a qualificação e melhoria dos procedimentos relativos à educação ambiental. Assim, acredita-se que os resultados obtidos por meio do desenvolvimento desta proposta poderiam contribuir para repensar o processo de inserção da educação ambiental em contextos educativos institucionais e para a elaboração de políticas públicas coerentes com as necessidades manifestadas pelas docentes, tendo em vista o papel preponderante que estas desempenham na conjuntura das mudanças sociais.

As considerações tomadas aqui, com base na embate entre a teoria e a empiria, se fazem necessárias; pois é na constatação e na discussão destas 'pequenas' realidades - muitas vezes supostamente tidas como óbvias - que se criam as oposições, se organizam e se consolidam os campos de estudo e se fortalecem os movimentos de questionamento e problematização de uma lógica vigente que, temos visto cotidianamente na prática, é socialmente e ecologicamente desequilibrada.

\section{REFERÊNCIAS}

1. BRASIL. Decreto-lei no 9.795, de 27 de abril de 1999.

2. CARTEA, P. A. M. Las barreras sociopolíticas para la práctica de uma educacíon ambiental radical em lãs sociedades avanzadas: lo que podemos aprender de la basura. In: Anais do $\mathrm{V}$ Congresso Iberoamericano de Educação Ambiental, 5o ed., Joinville, 2006.

3. FRABBONI, F. La educación del niño de cero a seis años. Madrid: Cincel, 1996.

4. GARCíA, J. E. Educacíon Ambiental, constructivismo y complejidad. Montequinto-Sevilla: Díada Editora S.L, 2004.

5. LAYRARgueS, P. Prefácio. In: SANTOS, J. E.; SATO, M. A contribuição da Educação Ambiental à Esperança de Pandora. São Carlos: Rima, pp. 13-18, 2001.

6. LAYARGUES, P. O cinismo da reciclagem: o significado ideológico da reciclagem da lata de alumínio e suas implicações para a educação ambiental. In: LOUREIRO, F.; LAYARGUES, P.; CASTRO, R. (Orgs.). Educação ambiental: repensando o espaço da cidadania. São Paulo: Cortez, 2002.

7. LIMA, G. F. C. Educação, Emancipação e Sustentabilidade: em defesa de uma pedagogia libertadora para a Educação Ambiental. In: LAYRARGUES, P. (Coord.) Identidades da Educação Ambiental Brasileira. Brasília: Ministério do Meio Ambiente, 2004.

8. LOUREIRO, C. F. B. Trajetórias e fundamentos da educação ambiental. São Paulo: Cortez, 2004.

9. MORALES, A.G.; KNECHTEL, M.R. A universidade e a formação em educação ambiental na perspectiva multicultural: considerações e possibilidades. In: MORALES, A.G. et al. Educação ambiental e multiculturalismo. Ponta Grossa: Editora UEPG, 2012.

10. PARRA ORTIZ, J. M. La Educación Infantil: su dimensión didática y organizativa. Madrid: Grupo Editorial Universitario, 2005.

11. Referencial Curricular Nacional para a Educação Infantil (1998, p. 27). Disponível em: 
<http://portal.mec.gov.br/seb/arquivos/pdf/volume2.pdf>. Acesso em: 01/04/2012.

12. TARDIF, M. Saberes docentes e formação profissional. Petrópolis: Vozes, 2002.

13. Um Pouco da História da Educação Ambiental. Disponível em: <portal.mec.gov.br/secad/arqui vos/pdf/educacaoambiental/hitoria.pdf> Acesso em: 03/11/2011. 